\title{
Immediate Effect of Twin Block Appliance on the Airway on a Sample of Patients with Class II division 1 Malocclusion on Skeletal II Base
}

Khalil WS ${ }^{1}$, Mageet $\mathrm{AO}^{2,3^{*}}$

${ }^{1}$ Department of Orthodontics, faculty of Dentistry, University of Khartoum, Khartoum, Sudan.

${ }^{2}$ Associate Prof. of Orthodontics, Mohammed Bin Rashid University, HBM College of Dental Medicine, Dubai, UAE.

${ }^{3}$ Joint Fellow, Department of Orthodontics, Faculty of Dentistry, University of Khartoum, Khartoum, Sudan.

\section{Abstract}

There is a background relationship between the mode of breathing and antero-posterior jaw relation. Severe mandibular deficiency has been linked to reduced oropharyngeal airway dimension. Dental literature reported many studies on functional appliances and their effects, but there are few published studies on their effects on the airway.

Objectives: To investigate the immediate effect of the Twin block (TB) functional appliance on the airway in patients with class II division1 malocclusion on skeletal II base and to measure the immediate changes in the position of the hyoid bone after insertion of the TB appliance.

Materials and Methods: Two lateral cephalometric radiographs were taken and analyzed one before and one after insertion of the TB appliance for the 19 patients. The age range 10-14 years. Immediate change in the airway was performed by measuring the changes in the vertical position of the hyoid bone relative to the mandibular plane (H1) and to the (cv3-RGN) plane (H2). The change in the airway can be measured by the change in the vertical position of the hyoid bone before and after insertion of TB appliance $\left(\mathrm{H}_{-} \mathrm{H}_{1}\right)+\left(\mathrm{H}-\mathrm{H}_{2}\right)$.

Results: The hyoid bone changes in a more superior position after the insertion of the TB appliance. The mean change was $11.8 \mathrm{~mm}$, with SD $2.8 \mathrm{~mm}(P=0.0001)$ at $0.01 \%$ level.

Conclusion: Vertical hyoid bone position was changed in a more superior position immediately after the insertion of the TB appliance on patients with class II division 1 malocclusion on skeletal II base. Further, the TB has an immediate positive effect in the airway.

Keywords: Twin Block; Vertical Hyoid Bone Position; Cephalometric Radiograph; Obstructive Sleep Apnoea.

\section{Introduction}

Functional appliances (FAs) are orthodontic appliances designed to induce a change in activity of the various muscles which influence the function and position of the mandible in order to transmit forces to the dentition and the basal bone $[1,2]$.

Robin in early 1900 used an intra oral appliance to bring the lower jaw forward in newborn with mandibular deficiency, by preventing posterior relocation of the tongue during sleep; the same con- cept was used in FAs [3]. The Monoblock developed by Robin in the early 1900 was considered to be the forerunner of all FAs; however the activator developed by Andresen in Norway in 1920 was the first FA to be widely accepted [1].

Clark in 1977 developed and fitted the first Twin block (TB) appliance [4]. TB appliance is the most popular and versatile of all FAs as it's more comfortable, esthetically accepted and easy to fabricate [4].

FAs have been used to correct skeletal class II and class III maloc-



Citation: Khalil WS, Mageet AO (2017) Immediate Effect of Twin Block Appliance on the Airway on a Sample of Patients with Class II division 1 Malocclusion on Skeletal II Base. Int J Dentistry Oral Sci. 4(4), 464-470. doi: http://dx.doi.org/10.19070/2377-8075-1700091

Copyright: Mageet $\mathbf{A O}^{\circ}$ 2017. This is an open-access article distributed under the terms of the Creative Commons Attribution License, which permits unrestricted use, distribution and reproduction in any medium, provided the original author and source are credited. 
clusions [5]. These changes were due to enhancement of neuromuscular activity [5]. This in turn, modified mandibular and maxillary growth while guiding the eruption of teeth into more acceptable relationship [5].

When using FAs to treat malocclusion a special consideration of the adequacy of the respiratory function is important, the size and shape of nasopharyngeal space must be adequate for functional demands [6]. There is a relationship between the mode of breathing and antero-posterior jaw relation [6].

Özbek in 1997 reported a relationship between FAs treatment and airway, and stated that respiratory function influences the posture of the mandible, therefore the tongue, hyoid bone, head and neck posture and nasal airway maintenance provide important physiologic bases for FA therapy [7]. Severe mandibular deficiency has been linked to reduced oropharyngeal airway dimension $[7,8]$.

Decreased space between the cervical column and the mandibular body may lead to posterior postured tongue and soft palate, increasing the chances of impaired respiratory function and possibly causing problems such as snoring, upper airway resistance syndrome and obstructive sleep apnoea hypopnoea syndrome [OSAHS] [7, 9, 10].

The position of the hyoid bone serves as a central anchorage for the tongue muscles and determines the position of the tongue [11]. A lower hyoid bone position might be compensatory mechanism to alleviate the increase airway resistance caused by reduced airway space or as a result of greater tongue mass [11]. The anatomical normal position of the hyoid bone was consistently above and near the line from the antero-inferior point of the third cervical vertebrae (cv3) to Menton (Me) from the primary to the early permanent dentition [12-14]. Dental literature has many studies on FAs and their effects, but there are few published studies on their effects on the airway.

Dental literature has many studies on FAs and their effects, but there are few published studies on their effects on the airway. In addition FAs are usually bulky and thick; therefore, the parents become hesitant when these appliances are prescribed. They feel that their thickness may complicate their respiration. So; data needed to explain the exact improvement on the airway with TB appliance treatment.

The objective of this paper is to investigate the immediate effect of the TB appliance on the airway on patient with class II division 1 malocclusion on skeletal II base and measure the immediate changes in the position of the hyoid bone after insertion of the TB appliance.

\section{Material and Method}

Through a prospective analytical design a sample of 19 patients of class II division 1 malocclusion (British Standard Institute Classification, 1983) on skeletal II base will follow a cephalometric analysis before and after insertion of the twin block.

\section{Appliance Design}

Maxillary and mandibular impressions were taken with a normal and forward bite for the construction of the TB appliance. One design is fabricated for the 19 patients. Adams clasps for maxillary permanent $1^{\text {st }}$ molars and mandibular $1^{\text {st }}$ premolars, triangular clasps distal to maxillary $1^{\text {st }}$ premolars, short labial bow (.07” Stainless steel in relation to maxillary anteriors, occlusal capping for the mandibular incisors and the maxillary and mandibular blocks (length $7 \mathrm{~mm}$ and $60^{\circ}$ angulation).

A lateral cephalometric radiograph taken at the time of records and another radiograph was taken after insertion of the TB appliance for the 19 patients; consent is taken before taking records, where the whole procedure is explained clearly to the parents.

The patient was seated in the radiographic unit (cranex $3+$ ceph cephalostat, Orion corporation sordex ${ }^{\mathrm{TM}}$ ) and cephalometric radiograph was taken by a trained radiographer.

The cephalometric radiograph was taken on a standard Siemens cephalostat. The distance from the tube target ( $\mathrm{x}$-ray source) to the subject's mid-sagittal plane was $152.4 \mathrm{~cm}$ with a $20 \mathrm{~cm}$ distance from mid-sagittal plane to the film. Lateral cephalometric radiograph was taken in natural head position (mirror method) as defined by Solow and Tallegran [15], and teeth in centric occlusion and exposure at $70 \mathrm{KV}, 10 \mathrm{MA}$ for 1.2 seconds, with right side of patient facing the cassette.

Magnification was calculated according to the formula:

$$
\begin{aligned}
& \text { Magnification }=\left(\frac{\text { Focal film distance }}{\text { Focal film distance }- \text { Object film distance }}\right)-1 \times 100 \\
& (\text { Magnification }=170 /(170-20)-1 \times 100=13 \%) .
\end{aligned}
$$

A green sensitive film MXG (18x24cm) developed with standard wet processing technique. Tracing is done by the same operator using a sharp pencil (Rotring 0.5) on acetate paper over illuminated opal light box, certain anatomic points was marked.

In the present study used hard tissue measurement to see the changes on the airway because the tongue and soft palate are soft tissues that are sometimes unclear on routine cephalogram. The hyoid bone can be easily identified on radiographs and make better differentiation on airway.

The landmarks (Figure 1 \& Table 1), linear (Figure 2 \& Table 2) and angular (Figure 3 \& Table 3 ) measurements were used. The linear measurements were corrected for magnification. The change in the airway can be measured by the change in the vertical position of the hyoid bone before and after wearing the Mandibular repositioning appliance [16].

\section{Reliability of Measurement}

All procedures for measurement calculation (tracing, landmark identification) was done and repeated by same investigator after one week. Tracing error was evaluated by retracing 5 randomly selected cephalometric radiographs.

The first and second measurement was compared using Dahlberg's formula: 
Figure 1. Anatomic Landmarks.



Table 1. Definitions of the Anatomic Landmarks.

\begin{tabular}{|l|l|}
\hline \multicolumn{1}{|c|}{$\begin{array}{c}\text { The } \\
\text { Landmarks }\end{array}$} & Definition \\
\hline $\mathrm{N}$ & Nasion: The most anterior point of the fronto-nasal suture. \\
\hline $\mathrm{S}$ & Sella: The midpoint of the sella tursica. \\
\hline ANS & Anterior Nasal Spine: The tip of the anterior nasal spine. \\
\hline PNS & Posterior Nasal Spine: The tip of the posterior nasal spine. \\
\hline $\mathrm{Me}$ & Menton: The lower most point on the mandibular symphesis in the midline \\
\hline Go & $\begin{array}{l}\text { Gonion: The intersection of the line connecting the most distal aspect of the condyle to the distal } \\
\text { border of the ramus and the mandibular plane. }\end{array}$ \\
\hline RGN & The most infero-posterior point on the mandibular symphesis. \\
\hline cv3ia & The infero-anterior point of the body of the third cervical vertebra. \\
\hline $\mathrm{H}$ & The upper edge of the frontal area of hyoid body. \\
\hline $\mathrm{H}_{1}$ & Perpendicular from $\mathrm{H}$ to the mandibular plane (Go-Me) \\
\hline $\mathrm{H}_{2}$ & Perpendicular from $\mathrm{H}$ to the line RGN-cv3ia \\
\hline
\end{tabular}

Figure 2. Linear Measurement.

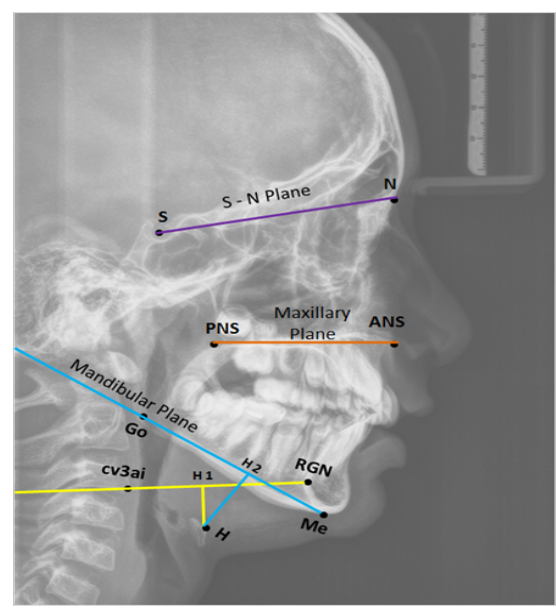

$$
M E=\sqrt{\frac{\sum d^{2}}{2 n}}
$$

$M E=$ method error

$d=$ different between first and second reading

$n=$ repeated reading

\section{Statistical analysis}

The data was analyzed by the Statistics Package for Social Science (SPSS) program version 17. Descriptive statistics (mean, standard deviation and range) was used to describe the sample. The difference between variables before and after insertion of the TB was compared using nonparametric paired $t$-test. Pearson correlation was used to correlate overjet and ANB (pre-treatment) to the changes after insertion of the TB appliance. The level of significance was set at $P=0.05$. 
Table 2. Definitions of Linear Measurements.

\begin{tabular}{|l|l|}
\hline \multicolumn{1}{|c|}{ Linear Measurements } & \multicolumn{1}{c|}{ Definition } \\
\hline S-N Plane & The line through points N and S. \\
\hline Maxillary Plane & The line connecting ANS with PNS. \\
\hline Mandibular Plane & The line connecting Me to Go. \\
\hline OJ & $\begin{array}{l}\text { Overjet: The horizontal distance between the palatal surface of the most proclined } \\
\text { upper incisor to the labial surface of the lower incisors. }\end{array}$ \\
\hline $\mathrm{H}-\mathrm{H}_{1}$ & The linear distance along a perpendicular from hyoid (H) to the Mandibular plane. \\
\hline $\mathrm{H}-\mathrm{H}_{2}$ & The linear distance between hyoid $(\mathrm{H})$ and a perpendicular to the cv3ia-RGN plane. \\
\hline$\left(\mathrm{H}-\mathrm{H}_{1}\right)+\left(\mathrm{H}-\mathrm{H}_{2}\right)$ & Vertical Hyoid Position. \\
\hline
\end{tabular}

Figure 3. Angular Measurements.

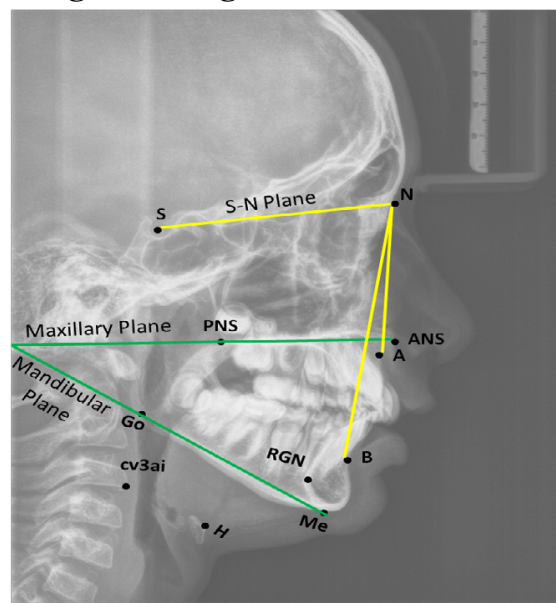

Table 3. Angular Measurement.

\begin{tabular}{|l|l|}
\hline \multicolumn{1}{|c|}{ Angular Measurements } & \multicolumn{1}{c|}{ Definition } \\
\hline SNA-SNP & The maxillary plane. \\
\hline Me-Go & The mandibular plane. \\
\hline SNA-SNP / Me-Go & The maxillary mandibular plane angle. \\
\hline SNA & Sella-Nasion-A point. \\
\hline SNB & Sella-Nasion-B point. \\
\hline ANB & Point A - Nasion - Point B. \\
\hline
\end{tabular}

\section{Results}

To test the reliability of the measurement, tracing error will be evaluated by retracing 4 randomly selected cephalographic after one week by the same investigator. The initial and repeated measurement was compared using Dahlberg's formula. The result was in 0.03 error; all of the measurements were free of systematic error. The descriptive statistics (mean, standard deviation and range) for the data in the two groups were measured (Table 4). The data analyzed using Student's paired $t$-test to evaluate the changes and the difference between the mean in the sample before and after insertion of the TB appliance, the $p$-value was determined (Table 5) represents real change in vertical hyoid bone position (Table 6).

Table. 4 shows the mean and the standard deviation of each variable in the sample $(\mathrm{N}=19)$, standard error of the mean and the range were also calculated.

Table. 5 represent the mean difference of change in $\mathrm{H}_{1}$ is $(6.4 \mathrm{~mm}$, SD 1.8), mean difference in $\mathrm{H}_{2}$ is $(5.5 \mathrm{~mm}, \mathrm{SD} 2.0)$ and for the combined is $(11.8 \mathrm{~mm}$ SD 2.8$)$ and all changes is highly significant with $P=0.0001)$

The changes in the vertical position of the hyoid bone show a mean of $11.8 \mathrm{~mm}$ and Std. Deviation of 2.8. The minimum change is $4.8 \mathrm{~mm}$ and maximum is $16.8 \mathrm{~mm}$.

Pearson correlation was used to correlate the relationship between changes of the hyoid bone position to the ANB and overjet (pre-treatment) is shown with a high correlation between the changes of the hyoid bone position and the pre treatment overjet and weak correlation to the ANB (Table 6).

\section{Discussion}

Children with Class II/1 malocclusion on skeletal II base have a narrower or-and hypo pharyngeal space than Class I occlusion [17]. There is relationship between functional orthopedic treatment and increase in OAW dimension in the skeletal class II patients as described by Özbek [7] in 1998 who found that the use of functional appliances to increase the mandibular growth lead to improvement in the airway dimension in children with class II malocclusion. The present study $(\mathrm{n}=19)$ included patients with 
Table 4. Descriptive Statistics of the Variables.

\begin{tabular}{|l|l|l|l|l|l|l|}
\hline \multicolumn{2}{|c|}{ Variables } & N & Mean & $\begin{array}{c}\text { Standard } \\
\text { Deviation }\end{array}$ & $\begin{array}{c}\text { Standard Error } \\
\text { of the Mean }\end{array}$ & Range \\
\hline \multirow{2}{*}{$\mathrm{H}-\mathrm{H}_{1}$} & Before & 19 & 12.4 & 3.0 & 0.7 & 13.6 \\
\cline { 2 - 8 } & After & 19 & 6.0 & 2.5 & 0.6 & 10.4 \\
\hline \multirow{2}{*}{$\mathrm{H}-\mathrm{H}_{2}$} & Before & 19 & 7.4 & 2.4 & 0.5 & 7.2 \\
\cline { 2 - 7 } & After & 19 & 1.9 & 3.3 & 0.8 & 9.6 \\
\hline \multirow{2}{*}{$\left(\mathrm{H}-\mathrm{H}_{1}\right)+\left(\mathrm{H}-\mathrm{H}_{2}\right)$} & Before & 19 & 19.8 & 4.3 & 1.0 & 16 \\
\cline { 2 - 7 } & After & 19 & 7.9 & 4.2 & 1.0 & 12.8 \\
\hline
\end{tabular}

Table 5. Mean differences of changes between the two groups (Paired t-test).

\begin{tabular}{|c|c|c|c|c|c|c|c|}
\hline \multirow[t]{2}{*}{ Variables } & \multirow[t]{2}{*}{$\begin{array}{l}\text { Mean Difference } \\
\text { (before -after) }\end{array}$} & \multirow[t]{2}{*}{$\begin{array}{l}\text { Standard } \\
\text { Deviation }\end{array}$} & \multirow[t]{2}{*}{$\begin{array}{c}\text { Standard } \\
\text { Error of the Mean }\end{array}$} & \multicolumn{2}{|c|}{$\begin{array}{l}95 \% \text { Confidence } \\
\text { Interval of the } \\
\text { Difference }\end{array}$} & \multirow[t]{2}{*}{ df } & \multirow[t]{2}{*}{$\begin{array}{l}\text { Sig. } \\
\text { (2-tailed) }\end{array}$} \\
\hline & & & & Lower & Upper & & \\
\hline $\mathrm{H}-\mathrm{H}_{1}$ & 6.4 & 1.8 & 0.4 & 5.5 & 7.2 & 18 & 0.0001 \\
\hline $\mathrm{H}-\mathrm{H}_{2}$ & 5.5 & 2.0 & 0.5 & 4.5 & 6.4 & 18 & 0.0001 \\
\hline$\left(\mathrm{H}-\mathrm{H}_{1}\right)+\left(\mathrm{H}-\mathrm{H}_{2}\right)$ & 11.8 & 2.8 & 0.6 & 10.5 & 13.2 & 18 & 0.0001 \\
\hline
\end{tabular}

$*$ Paired t-test performed. $* * * * \mathrm{P}<.0001$.

Table 6. Correlation of Overjet and ANB Measures (pre-treatment) with Changes.

\begin{tabular}{|l|l|c|}
\hline Variables & Pearson Correlation & Sig. \\
\hline Overjet & 0.635 & 0.003 \\
\hline ANB & 0.444 & 0.057 \\
\hline
\end{tabular}

$$
\mathrm{P}<0.001 .
$$

Figure 4. The twin block appliance in place.

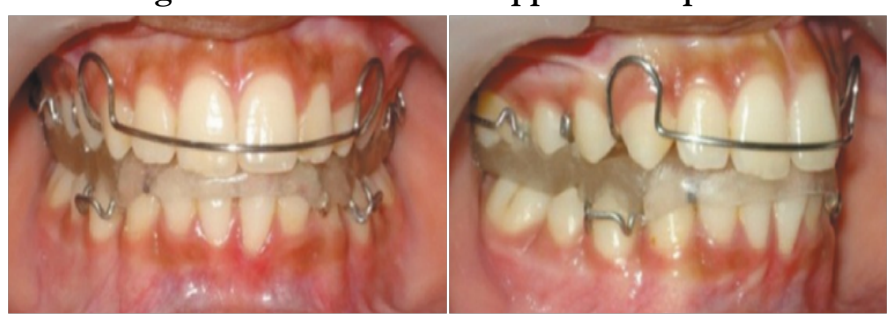

Table 7. Comparisons between the Result of the Present Study and Previous Reported Studies.

\begin{tabular}{|c|c|c|c|c|c|c|c|}
\hline \multirow[b]{2}{*}{$\begin{array}{l}\text { Studies } \\
\text { (authors) }\end{array}$} & \multirow[b]{2}{*}{ Sample size } & \multirow[b]{2}{*}{$\begin{array}{l}\text { Appliance } \\
\text { used }\end{array}$} & \multicolumn{4}{|c|}{ Results } & \multirow[b]{2}{*}{ Sig. } \\
\hline & & & $\begin{array}{c}\mathrm{H}_{1} \\
\text { mean } \\
\text { difference }\end{array}$ & SD & \begin{tabular}{c|}
$\mathrm{H}_{2}$ \\
mean \\
difference
\end{tabular} & SD & \\
\hline Present study & $\begin{array}{l}19 \text { class II/1 growing } \\
\text { children }\end{array}$ & TB & 6.4 & 1.8 & 5.5 & 2.0 & 0.0001 \\
\hline $\begin{array}{l}\text { Kirjavainen M, et } \\
\text { al., } 2007 \text { [17] }\end{array}$ & $\begin{array}{l}40 \text { patients with class II } \\
\text { malocclusion }\end{array}$ & $\begin{array}{l}\text { Cervical head } \\
\text { gear }\end{array}$ & 0.4 & 2.2 & 0.6 & 2.6 & 0.05 \\
\hline $\begin{array}{l}\text { Kyung SH, et al., } \\
2005\end{array}$ & 14 patients with OSAHS & $\begin{array}{l}\text { Mandibular } \\
\text { protruding de- } \\
\text { vice (MPD) }\end{array}$ & & & & & $\begin{array}{l}\text { Open airway } \\
\text { positively }\end{array}$ \\
\hline $\begin{array}{l}\text { Lawton HM et al., } \\
2005\end{array}$ & $\begin{array}{l}16 \text { patients } \\
\text { with OSAHS }\end{array}$ & TB & & & & & $\begin{array}{l}\text { Open airway } \\
\text { positively }\end{array}$ \\
\hline $\begin{array}{l}\text { Anette M et al., } \\
2002[32]\end{array}$ & $\begin{array}{l}65 \text { patients } \\
\text { with OSAHS }\end{array}$ & $\begin{array}{l}\text { Mandibular } \\
\text { protruding } \\
\text { device (MPD) }\end{array}$ & 1.6 & 3.0 & & & $<.001$ \\
\hline
\end{tabular}


class II/1 malocclusion on skeletal II base with age range 10-14 years; TB appliance design with acrylic coverage for the lower incisors was used for the treatment. The immediate change in the airway was measured by the change in the vertical position of the hyoid bone relative to the mandibular plane and (cv3ai - RGN) plane before and after insertion. The hyoid bone position changed more superior in relation to the mandibular plane after insertion of the TB appliance, the mean difference in $\mathrm{H}_{1}$ was $(6.4 \mathrm{~mm}$, SD $1.8, P=0.0001)$. This result was in agreement with the result of Kirjavainen [17] who studied the effect of the head gear on the airway on children with class II skeletal. The mean difference of the change in the vertical hyoid bone position $\left(\mathrm{H}_{2}\right)$ in relation to the (cv3ai-RGN) plane was $(5.5 \mathrm{~mm}, \mathrm{SD} 2.0, P=0.0001)$. Kirjavainen found a higher mean change of $(0.6 \mathrm{~mm}, \mathrm{SD} 2.6)$ [17]. Historically, OAs used in treating OSAHS is predominantly derived from functional appliances. OAs is an established therapeutic option for treating obstructive sleep-disordered breathing; it showed a high success rate in treating OSAHS [18-28].

Lawton in 2005 used the TB and Herbst appliances in patients with OSAHS and found that the two appliances have an effect on opening the airway but TB appliance is more effective, the present study show same positive effect of the TB appliance on the airway when used to treat children with class II/1 malocclusion on skeletal II base [28]. There was a high significant difference between the change of the hyoid bone position and the pre treatment overjet $(P=0.003)$ and a low significant difference with the ANB $(P=0.057)$. The final change in the vertical hyoid bone position in the present study is highly significant $(11.8 \mathrm{~mm}, \mathrm{SD}$ $2.8, P=0.0001)$. This change represents the change in the airway after insertion of the TB appliance.

Using TB functional orthopedic lead to improvement in airway dimension in children with class II malocclusion this same result also found by Özbek [7] by using functional orthopedic lead to improvement in airway dimension in children with class II/1 malocclusion on skeletal II base. This present study demonstrated that the hyoid bone moved superiorly after mandibular advancement. This movement opened the airway and increase inspiratory and expiratory total air $[30,31]$.

Kyung et al., 2005 found that oral appliance appears to enlarge the pharynx to a greater degree in the lateral than in the sagittal plane at the of the pharynx and suggesting a mechanism for the effectiveness of oral appliances that protrude the mandible and open airway [30], the findings of the present study confirm that TB appliance as mandibular advancement device open the airway positively. The hyoid bone adopts more down and forward position relative to the mandible as the position of the supra and infra hyoid muscle is altered [10]. Pharyngeal size and shape differences between pre-and post trials of a mandible-protruding oral appliance advancing the mandible forward to enlarge the pharynx could be considered an alternative to continuous positive air pressure (CPAP) therapy [21]. Mandibular repositioning devices improved the inspiratory and expiratory total air and decrease nasal resistance in mild to moderate OSAHS $[30,31]$.

\section{Conclusion}

With the use of TB functional appliance in the treatment of CL II/1 malocclusion on skeletal II base it was concluded that:
- Placement of TB appliance on patients with class II/1 malocclusion on skeletal II base revealed that the vertical hyoid bone position was changed immediately in a more superior position in relation to its position at insertion.

- TB appliance has immediate positive effect on the airway.

- It can be suggested that the TB appliance could be used in the treatment of mild to moderate OSAHS in growing patients.

We recommend having larger sample size with a long term follow up to see the stability of the changes on the airway after using TB appliance in patients with class II/1 malocclusion on skeletal II base.

\section{References}

[1]. Proffit W (2007) Contemporary Orthodontics. (4th edn), 397- 402.

[2]. Bishara SE, Ziaja RR (1989) Functional appliances: a review. Am J Orthod Dentofacial Orthop. 95(3): 250-58.

[3]. Robin P (1934) Glossoptosis due to atresia and hypotrophy of the mandible. Am J Dis Child 48(3): 541-47.

[4]. Clark WJ (1988) The Twin block technique: a functional orthopedic appliance system. Am J Orthod Dentofacial Orthop. 93(1): 1-18.

[5]. Yamin CL, Woodside DG, Sektakof PA, Sessle BJ (1997) The action three types of functional appliances on the activity of the masticatory muscles. Am J Orthod Dentofacial Orthop. 112(5): 560-72.

[6]. Graber TM (1997) Dentofacial Orthopedics with Functional Appliances. (2nd edn), Mosby. $16-23$

[7]. Özbek MM, Toygar UT (1998) Oropharyngeal airway dimensions and functional-orthopedic treatment in skeletal class II cases. Angle Orthod. 68(4): 327-36

[8]. Figuero AA, Glupker TJ, Fitz MG (1991) Mandible, tongue and airway in Pierre Robin Sequence: A longitudinal cephalometric study. Cleft Palate Craniofac J. 28(4): 425-34.

[9]. Scottish Intercollegiate Guidelines Network Report (SIGN), June 2003.

[10]. Özbek MM, MiyamotoK, Lowe AA (1998) Natural head posture, upper airway morphology and obstructive sleep apnea severity in adult. Eur J Orthod. 20(2): 133-43.

[11]. Tsai HH, Yin Ho C, Lee LP (2007) Cephalometric analysis of non-obese snorers either with or without obstructive sleep apnea syndrome. Angle Orthod. 77(6): 1054-61.

[12]. Karlsen AT (2004) Association between vertical development of the cervical spine and face in subjects with varying vertical facial patterns. Am J Orthod Dentofacial Orthop. 125(5): 597-606.

[13]. Hellsing E, Forsberg CM, Linder Aronson S, Sheikholeslam A (1986) Changes in postural EMG activity in the neck and masticatory muscles following obstruction of the nasal airways. Euro J Orthod. 8(4): 247-53.

[14]. Tsai HH (2002) The positional changes of hyoid bone in children. J Clin Pediatr Dent. 27(1): 29-34.

[15]. Solow B, Tallegran A (1971a) Natural head position in standing subjects. Acta Odontol Scand 29(5): 591-607.

[16]. Mageet AO, Khamis AH, McDonald JP (2015) Obstructive Sleep Apnoea Hypopnoea Syndrome and the Cranio-facio-hyoid Morphology in Adults: Linear and Angular Measurements. Ann Clin labo Res. 3(4:36): 1-8.

[17]. Kirjavainen Mirja, Kirjavainen Turkka (2003) Maxillary Expansion in Class II Correction with Orthopedic Cervical Headgear. A Posteroanterior Cephalometric Study. The Angle Orthodontist. 73(3): 281-285.

[18]. Lofstrand TB (1995) Snoring, sleep apnoea and dental occlusion. An epidemiological study of 4-year-olds. Eur J Orthod. 17: 343-52.

[19]. Caldwell S, Cook P (1992) Predicting the outcome of twin block functional appliance treatment: a prospective study. Eur J Orthod. 21(5): 533-39.

[20]. Kollias I, Krogsta O (1999) Adult cranio-cervical and pharyngeal changes -a longitudinal cephalometric study between 22 and 42 years of age. part1: morphological cranio-cervical and hyoid bone changes. Eur J Orthod. 21(4): 333-34.

[21]. Malkoc S, Usumez S, Nur M, Donaghy CE (2005) Reproducibility of airway dimensions, tongue and hyoid bone on lateral cephalogram. Am J Orthod Dentofacial Orthop. 128(4): 513-16.

[22]. Mehta A, Qian J, Petocz P (2001) A randomized clinical controlled study of a mandibular advancement splint for obstructive sleep apnoea. Am J Respir Crit Care Med. 163(6): 1457-61. 
[23]. Horiuchi A, Suzuki M, Ookubo M (2005) Measurement techniques predicting the effectiveness of an oral appliance for Obstructive Sleep Apnoea Hypopnea Syndrome. Angle Orthod. 75(6): 1003-11.

[24]. Gale D, Sawyer R, Woodcock A, Stone P (2000) Do oral appliances enlarge the airway in patients with obstructive sleep apnoea? A prospective computerized tomographic study. Eur J Orthod. 22(2): 159-68.

[25]. Rose CE, Barthlen MG, Staats R (2002) Therapeutic efficacy of an oral appliance in the treatment of obstructive sleep apnoea: A 2-year follow-up. Am J Orthod Dentofacial Orthop. 121(3): 273-79.

[26]. Liu Y, Zeng X, FuM, Haung X, Lowe AA (2000) Effects of a mandibular repositioner on obstructive sleep apnea. Am J Orthod Dentofacial Orthop. 118(3): 248-56

[27]. Bonham PE, Currier GF, Orr WC, Othman J, Nanda RS (1998) The effect of modified functional appliance on obstructive sleep apnoea. Am J Orthod Dentofacial Ortho. 94(5): 384-92.

[28]. Lawton ML, Battagel JM, Kotecha B (2005) A comparison of the twin block and Herbst mandibular advancement splint in the treatment of patients with obstructive sleep apnea: a prospective study. Eur J Otrhod. 27(1): 82-90.

[29]. Kyung SH, Park YC, Pae EK (2005) Obstructive sleep apnea patients with the oral appliance experience pharyngeal size and shape changes in three dimensions. Angle Orthod. 75(1): 15-22.

[30]. Mageet AO, McDonald JP (2014) Effect of Mandibular Repositioning Ap- pliances on Inspiratory and Expiratory Total Air. Appl Clin Res Clin Trials Regul Affairs. 1: 1-8

[31]. Mageet AO, Khamis AH, McDonald JP (2015) Effect of Mandibular Repositioning Appliances on Nasal Resistance of a sample of obstructive sleep apnoea hypopnoea syndrome patients. Intl J Scientific Res. 4(5): 1-4.

[32]. Anette MC Fransson, Åke Tegelberg, Björn AH Svenson, Bertil Lennartsson, Göran Isacsson (2002) Influence of mandibular protruding device on airway passages and dentofacial characteristics in obstructive sleep apnea and snoring. Am J Orthod Dentofacial Orthop. 122(4): 371-379. 